Bulletin d'Histoire Contemporaine de

l'Espagne

$50 \mid 2016$

Les intellectuels en Espagne, de la dictature à la démocratie (1939-1986)

\title{
Los intelectuales del franquismo entre 1939 y 1953
}

Les intellectuels du franquisme entre 1939 et 1945

The intellectuals of the Francoism between 1939 and 1945

Ismael Saz

\section{OpenEdition}

\section{Journals}

Edición electrónica

URL: http://journals.openedition.org/bhce/480

DOI: $10.4000 /$ bhce.480

ISSN: 1968-3723

Editor

Presses Universitaires de Provence

Edición impresa

Fecha de publicación: 1 diciembre 2016

Paginación: 33-42

ISSN: 0987-4135

Referencia electrónica

Ismael Saz, "Los intelectuales del franquismo entre 1939 y 1953 », Bulletin d'Histoire Contemporaine de I'Espagne [En línea], 50 | 2016, Publicado el 09 octubre 2018, consultado el 17 septiembre 2020. URL: http://journals.openedition.org/bhce/480 ; DOI : https://doi.org/10.4000/bhce.480 


\section{Los intelectuales del franquismo entre 1939 y 1953}

\section{Ismael SAZ}

Universitat de València

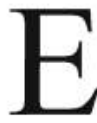

n las páginas que siguen se intentará, más que elabora una síntesis acerca del enunciado del artículo, encadenar una serie de reflexiones relacionadas con los problemas más relevantes sobre el tema de referencia. Se pretende con ello adecuar nuestro texto al marco general en que se inscribe, tanto como en lo relativo a éste monográfico. En este sentido, intentaremos definir en primer lugar nuestro objeto de referencia, para abordar seguidamente, de una forma crítica y abierta al debate y la confrontación de ideas, algunas de las cuestiones más debatidas al respecto.

\section{¿Quiénes eran los intelectuales del franquismo?}

Creo que no está de más constatar, como punto de partida, que los intelectuales más relevantes del franquismo en sus primeras décadas, los intelectuales de la victoria, eran, salvo excepciones, intelectuales que a la altura de 1936 lo eran-básicamente por su juventud-de «segunda fila». Y que si pasaron a serlo de "primera fila», lo fue en buena parte por el vacío generado -los «huecos» de que hablaría Laín, años más tarde, en diciembre de $1955^{\perp}$ - por la violencia en la guerra civil, el posterior exilio y la feroz represión cultural del régimen.

Y no hablamos ya de los intelectuales republicanos. Hablamos de la desaparición, en el campo falangista, de los Ramiro Ledesma, José Antonio Primo de Rivera y Onésimo Redondo; hablamos de la del referente del tradicionalismo, Víctor Pradera; hablamos de la de Ramiro de Maeztu en el sector del nacionalismo reaccionario, el de los monárquicos de Acción Española. Cierto que, en el primero de los campos citados estaban todavía los Sánchez Mazas, Giménez Caballero o Eugenio Montes. Pero los días de gloria intelectualfascista de Giménez Caballero habían pasado ya hacía tiempo, y no se puede decir que lo mejor de las aportaciones de los otros dos estuviera por llegar. Naturalmente, esto no quiere decir que no pudieran ser puntualmente importantes para y en el régimen. Pero sí que ya no estaban en primer plano en la elaboración ideológica o política. También en el campo de los monárquicos reaccionarios quedaban los Eugenio Vegas Latapie, José María Pemán o José Pemartín. Pero la temprana automarginación del primero lo dejó pronto en la calidad de referente intelectual -más que de «constructor activo»-para las nuevas generaciones reaccionarias; mientras que Pemán asumió gustoso su cualidad de vocero retórico y cualificado de lo peor del franquismo; y el tercero, Pemartín, aún tendría tiempo

1 Aunque Laín hablaba únicamente de «huecos producidos por nuestra Guerra de Liberación». «Informe de Don Pedro Laín Entralgo respecto a la situación espiritual de la juventud española», Reproducido en Roberto MEsA (ed.), Jaraneros y alborotadores, Madrid, Editorial de la Universidad Complutense, 1982. La cita en p. 49. 
de reformular, en las condiciones de la Guerra civil y el naciente franquismo, casi a modo de canto del cisne, algunas de las premisas fundamentales de Acción Española ${ }^{2}$.

Había, claro, otros intelectuales de más difícil cualificación y, digámoslo así, localización. De los «grandes» de antes de la guerra, Unamuno había desaparecido, quedando su legado en el interior a merced del juego de condenas, apropiaciones y distorsiones en que se enfrascaron los distintos sectores intelectuales franquistas. Quedaban, por otra parte, entre otros, Ortega y Gasset y Eugenio D’Ors. Pero ¿dónde estaban? Uno, en un exilio lleno de ambigüedades hasta su vuelta, no menos ambigua, en 1945; el otro, plenamente incorporado al régimen, aunque no para que brillaran precisamente en esos momentos sus viejas e indiscutibles dotes intelectuales. Así que, entre silencios, ambigüedades y más o menos apacibles integraciones, Ortega y D'Ors quedaron como referentes para los «nuevos intelectuales». Para lo bueno y para lo malo, el Ortega que, como Unamuno, sería fustigado por el nacionalcatolismo y reivindicado por los falangistas. Para lo bueno, si bien de forma no especialmente relevante, Eugenio D’Ors, cuyo clasicismo mediterráneo había ido a aterrizar en la brutalidad integrista del cura azul -Fermín Yzurdiaga-; aunque su legado pudo encontrar un mejor receptor en Aranguren. Estaban también, en fin -y no pretendo en modo alguno ser exhaustivo-, los Baroja o Azorín, menos o más, por este orden, dispuestos a ser utilizados por el régimen o algunos de sus sectores.

\section{Intelectuales del poder}

Así pues, la "primera fila» de los intelectuales del franquismo iba a ser ocupada por los que, por razones de edad u otras, venían de la «segunda fila» en la España republicana. Eran los Ridruejo, Laín, Tovar, Maravall y Conde, entre otros, en las filas del falangismo; los Elías de Tejada en el tradicionalismo; y progresivamente, los Calvo Serer, Pérez Embid y tantos otros, entre los continuadores de Acción Española.

Decir, sin embargo, que venían de la segunda fila para ocupar la primera, no supone prejuzgar nada acerca de sus cualidades y potencialidades. Pero sí obliga a una ulterior precisión. Ésta es que estamos hablando de intelectuales políticos, intelectuales del poder e intelectuales en posiciones de poder; de unas posiciones de poder que, de hecho, jamás había tenido intelectual español alguno. Centrándonos de momento en los falangistas, basta recordar que controlaban -hasta 1941 al menos- la todopoderosa censura, es decir, determinaban lo que se podia y no se podía decir; controlaban la propaganda, ese elemento fundamental en todo régimen con ansias totalitarias; y controlaban la prensa, en particular, la más poderosa de cadenas de periódicos que haya existido nunca en España. No eran un gueto, ni del derecho ni del revés, como pretendería más tarde Laín Entralgo: eran el poder. Otra cosa es que no fuera el poder absoluto al que aspiraban, o que no tardaran demasiado tiempo en perder buena parte de sus posiciones.

Por otro lado, en lo que a las «cualidades» se refiere, cabe decir que estos intelectuales llegados al primer plano desde el segundo, aupados a esta posición por motivos políticos relacionados con la dinámica del régimen, no eran por ello analfabetos oportunistas, incultos de aluvión, «malos» o «pobres» intelectuales. Tenían cultura, tenían formación, tenían altas capacidades intelectuales y, si no, las alcanzarían y desarrollarían muy pronto. Es una cuestión de opinión, por supuesto, pero no creo que se pueda discutir a día de hoy

2 José Pemartin, Qué es «Lo Nuevo»... Consideraciones sobre el momento español presente, Santander, Cultura española, 1938. 
la calidad intelectual de los Laín, Tovar, Maravall, Conde, Ridruejo, etc. Al fin y al cabo, se habían formado en la "edad de plata» de la cultura española y en ella -y su apertura al mundo- encontraron sus nutrientes intelectuales. Otra cosa es el uso que hicieran de ellos.

\section{Lenguaje y fascismo}

Jordi Gracia ha escrito interesantes consideraciones, amparándose un tanto en Víctor Klemperer, acerca de ese carácter fundamental de los fascismos que es la perversión del lenguaje, de la lengua ${ }^{3}$. Y no le falta, desde luego, razón. O mejor, una parte de razón. No hay duda, por supuesto, de los efectos maléficos del fascismo en los planos de la irracionalidad, de la perversión del lenguaje, de su capacidad para adulterar la percepción de la realidad y, por supuesto, de la historia. Sucede, sin embargo, que el fascismo, que es todo esto, no es sólo esto. El fascismo es, también, un fenómeno que hunde sus raíces culturales e intelectuales en la Europa de finales del siglo XIX y principios del XX. Como ya demostrara Zeev Sternhell, no es algo ajeno a la cultura europea, no es algo caído del cielo -o del infierno-, ni desde luego una especie de virus o «enfermedad moral», noción de la que se alejó la historiografía sobre el fascismo hace ya varias décadas. Y entre sus raíces culturales, hay mucha cultura y mucha intelectualidad. Incluso el irracionalismo fascista tiene mucho de construcción intelectual -es, de hecho, una construcción intelectual-, de los intelectuales europeos que anticiparon o siguieron esa evolución; o, por decirlo de otro modo, encuentra muchos de sus anclajes en aquella auténtica revolución cultural que atravesó Europa en las décadas interseculares, del siglo XIX al XX'.

Consecuentemente, el fascismo no estaba reñido, en sí mismo, con toda la cultura europea. Tenía raíces intelectuales y tenía sus propios intelectuales. Y no eran «malos» o incultos. Es más, sabían escribir y sabían escribir con precisión. Se podrá decir cuanto se quiera acerca de las cualidades morales y políticas de la amplísima nómina de poetas, novelistas y, en otro terreno, sociólogos, politólogos o historiadores que abrazaron el fascismo o se sintieron fuertemente atraídos por él, pero difícilmente se podrá cuestionar que muchos de ellos ocupan un lugar, en absoluto marginal, en la cultura europea. Se trata por tanto de deslindar entre las prácticas legitimadoras -totalitarias- de los regímenes fascistas, por una parte, y los procesos de elaboración cultural y política, por otra. Ninguna duda en cuanto a la «perversidad» de las primeras, pero ninguna duda tampoco acerca del hecho de que el «irracionalismo» fascista sabia explicarse muy racionalmente, o de que muchos de sus intelectuales sabian expresarse desde una gran capacidad literaria, o de que sabían exponer con suma precisión conceptual sus argumentos y proyectos.

Pues bien, tampoco en esto -como en tantas otras cosas- hubo una excepcionalidad española. Porque, en efecto, si de algo no se puede acusar a los fascistas españoles -a los Laín, Tovar, Ridruejo o Maravall, por ejemplo- cuando eran perfectamente totalitarios, fascistas -y fascistas hitlerianos- es de no saber escribir, de falta de precisión conceptual. Escribian perfectamente, manejaban la lengua-Ridruejo, especialmente-con una precisión envidiable. Y no se aprecian grandes diferencias al respecto entre el Ridruejo de $1940 \mathrm{y}$ el de 1960, y lo mismo puede decirse de Laín, Tovar o Maravall: escribian muy bien -alguno

3 Jordi Gracla, La resistencia silenciosa, Barcelona, Anagrama, 2004, p. 21 y ss.

4 Zeev Sternhell, Mario Sznajder y Maia Asheri, El nacimiento de la ideología fascista, Madrid, Siglo XXI, 1994, p. 1 y ss. 
maravillosamente bien- en las primeras fechas y muy bien en las segundas. La diferencia radica en que en las primeras fechas eran fascistas y en las segundas no. Nada más que esto.

\section{Lo liberal y lo secular}

El fascismo es un fenómeno político laico y secular, postliberal y moderno. Podemos incluso convenir con Roger Griffin en que es una variedad del modernismo político, entendiendo como tal la condena de la modernidad en nombre de una modernidad alternativa ${ }^{5}$. En lo que aquí nos interesa, la voluntad de destruir el pasado para cimentar un «nuevo comienzo», de la sociedad, de la nación, del hombre, explica a la perfección el virulento antiliberalismo fascista. Porque se podía identificar políticamente al liberalismo como el responsable de todas las caídas, de todas las decadencias, de todos los males de la sociedad, de la nación, del hombre. Pero el referente es, como decíamos, postliberal: se trata de ir más allá del liberalismo que se destruye, pero no para volver al pasado, a un inventado Antiguo Régimen, como sí querrán los nacionalcatólicos reaccionarios de Acción Española. Ahora bien, también desde esta perspectiva, ese carácter postliberal del fascismo lo sitúa necesariamente en el plano de la cultura moderna, secular y laica. No podía romper con toda ella, porque ello supondría romper, pura y llanamente, con buena parte de sus orígenes culturales. De ahí que su furibundo antiliberalismo no pudiera volverse al modo torquemadiano nacionalcatólico contra la cultura secular.

También en este caso, los intelectuales fascistas españoles respondieron perfectamente a sus códigos ideológicos. No podían volverse, por las razones que decíamos antes y que apuntamos ahora, contra todo Unamuno, contra todo Azorín, Baroja u Ortega. Como tampoco podían hacerlo -aunque a veces no tuvieran más remedio que simular que lo hacían - contra todo Nietzsche, contra todo Sorel, D'Annunzio o Gentile, muchos de ellos en los índices de obras condenadas por el Vaticano.

Se puede precisar a partir de ahí que cuando los fascistas españoles, como el fascismo en general, mostraba su apertura intelectual hacia este tipo de intelectuales no lo hacían en base a una estrategia de la confusión, a la voluntad de dotarse de una, ficticia, patina de modernidad o la de confundir a propios y extraños. Estaban dialogando, simplemente, con sus propias raíces culturales.

Del mismo modo, cuando los fascistas pretendian integrar o «rescatar» a muchos de los intelectuales mencionados, no se estaban traicionando a sí mismos. Simplemente se aplicaban a la tarea de desgajar, despojar, purgar, todo lo que de liberalismo había en unos autores susceptibles de ser integrados a partir de ahí en la propia cosmovisión y, sólo a partir de ahí, en su propio bagaje cultural fascista. No otra cosa era la «síntesis» fascista. Pero esa síntesis no excluía, todo lo contrario, lo presuponía, el más radical antiliberalismo.

\section{"Integradores" y ferozmente antiliberales}

Descendiendo un poco a lo concreto, intentaremos ilustrar cuanto venimos diciendo con algunos ejemplos especialmente significativos.

Primero. El Ridruejo de Escorial y del rescate de Machado. No se ha llamado la atención, o no al menos suficientemente, en que «El poeta rescatado», aparece en Escorial con fecha

5 Rogger Griffin, Modernismo y fascismo. La sensación de comienzo bajo Mussolini y Hitler, Madrid, Akal, 2007. 
de 1 de noviembre de 1940, sólo tres días después de la publicación en Arriba de otro texto del propio Ridruejo, «La patria como síntesis», un artículo que se situaba en la más completa, radical y absoluta oposición al liberalismo. ¿Qué decía? Decía que la Patria era una unidad trascendente, como tenía que serlo la propia Falange, definida, además, como totalitaria, minoritaria, exclusiva y unitaria. La única con capacidad para decidir quien se integraba y quien no en la propia Falange, en el Estado y -nótese- en la Patria. Era la Falange la llamada a ocupar todos los espacios: «extremista de los dos extremos y centrista de la totalidad: absoluta y única». ¿Había algo de reconciliatorio en todo esto?, se preguntaba Ridruejo. Y contestaba: tal vez, pero, desde luego, nada de conciliatorio, porque, la unidad, decía, sólo podía ser una e impuesta, y no cabía más «concilio» que el de la «sumisión de todos a una norma», ni más norma que la «que se defiende resueltamente».

Segundo. El Laín que de buen fascista y católico había abonado en Los valores morales del nacionalcatolicismo la tesis de que sólo había una forma de ser católico español la nacionalsindicalista- $\mathrm{y}$ hasta se había permitido hacer jugosas advertencias a algunas jerarquías eclesiásticas, no se andaba con miramientos a la hora de referirse a los otros católicos ${ }^{6}$. A los españoles, por supuesto, con ese «liberalismo de tufos devotos» de las asociaciones católicas decimonónicas; o a esa deformación liberal de Acción Católica que explicaría las carencias en ella de «vigor combativo, pasión joven... forma deportiva» ${ }^{7}$. Y peor parados salían los católicos extranjeros reos de liberalismo. Así, en su «Aviso fraterno a los jóvenes americanos», les alertaba contra los peligros del «liberalismo catolizante o catolicismo liberalizado", de los del maritenismo o el cruzirrayismo, cosas que podían ser seductoras al principio pero que terminaban con la entrega del poder real al instinto, a «sacerdotes fusilados o quemados», a «misas de propaganda a sueldo de los comisarios del pueblo) $)^{8}$.

Tercero. Nadie cantó más y mejor al Estado totalitario, en Alemania, en Italia, en España y en Europa toda que José Antonio Maravall, quien no se privaba de afirmar que el Estado totalitario abría nada menos que una nueva época en la historia de la humanidad ${ }^{9}$. Pues bien, ese mismo Maravall, al unísono de las campañas contra el liberalismo del periódico en que colaboraba, Arriba, se cuidaba muy mucho de advertir contra las supervivencias del liberalismo, fueren cuales fueren y anidaren donde anidaren ${ }^{10}$.

Cuarto. Tampoco el Antonio Tovar que a la altura ya de 1948 se empeñaba en rescatar a Menéndez y Pelayo de los «menendezpelayistas», para darle un aire menos reaccionario, más moderno y «actual», mostraba mucho talante liberal cuando dirigía una dura reprimenda al cántabro por su conocida concepción acerca de la pluralidad cultural española:

Resulta difícil imaginarnos lo que hubiera sido la España plural y complicada con espíritus regionales no ya desiertos, sino exacerbados por la poesía de las lenguas vernáculas. El hecho es que la experiencia política acreditó sobradamente que en la poesía más desinteresada y alta termina por anidar el espíritu de disgregación política.

6 Pedro Lain Entral.go, Los valores morales del nacionalsindicalismo, Madrid, S. Aguirre, 1941.

7 Pedro Lain Entralgo, «Lo católico. 1. Raíz y sentido de las organizaciones católicas»; del mismo, «Lo católico. 4. El pensamiento de la Acción Católica»; ambos en Arriba España, 31 de enero de 1937 y 7 de marzo de 1937, respectivamente.

8 "Aviso fraterno a los jóvenes americanos», Escorial, n. ${ }^{\circ} 14$, diciembre de 1941.

9 José Antonio Maravall, «El sentido actual de la victoria»; también, «El totalitarismo, régimen europeo». Ambos en Arriba, 18 de agoto de 1940 y 26 de junio de 1940 , respectivamente.

10 Por ejemplo, «Desterrar el liberalismo» o «En torno a la ley sindical», ambos en Arriba, 27 de febrero de 1940 y 26 de enero de 1941 , respectivamente. 
$\mathrm{Y}$ sentenciaba "Actualidad ya no tiene esta parte de su pensamiento»" ${ }^{1}$.

Así pues, los intelectuales fascistas españoles asumían a la perfección las dos caras absolutamente inseparables del fascismo: la de la integración-apropiación de segmentos de la cultura secular moderna, en aras de la más compacta unidad de una comunidad nacional proyectada hacia el futuro, y el más profundo, visceral y absoluto rechazo del liberalismo.

¿Podian entonces, por talante o incluso involuntariamente, introducir elementos de continuidad con la «tradición liberal»? Creemos que, en función de todo lo dicho, es ahí precisamente donde radica el equívoco. Porque, por modernos y «modernistas», seculares y postliberales, podían -y efectivamente lo hicieron- introducir elementos de continuidad con la cultura secular. Pero cultura secular y cultura liberal no son necesariamente lo mismo. Es más, como se ha visto, era un tramo para nada despreciable de la cultura secular europea la que había puesto las bases para una eventual ruptura completa y total con el liberalismo. Y eso es lo que hicieron los fascistas españoles. Porque lo que reivindicaron, para apropiárselo, de la moderna cultura secular española era lo menos liberal de ella. Y lo que reivindicaban de Unamuno, Baroja, Azorín, Ortega, etc., eran sus facetas menos «liberales», aquellas que ellos estaban dispuestos a radicalizar y llevar al extremo en sentido fascista.

\section{Contra el liberalismo y la cultura moderna}

Por supuesto, todo esto podría parecer «liberal» si lo ponemos en relación con lo que pensaban, querían, decían y estaban dispuestos a imponer sus aliados-adversarios nacionalcatólicos, los de Acción Española, los que encontrarían su continuidad en los opusdeístas Calvo Serer y Pérez Embid, y en los, no menos reaccionarios, tecnócratas López Rodó y compañía.

Porque, en efecto, este nacionalismo reaccionario quería erradicar no sólo la cultura liberal, sino también el grueso de la cultura secular. Y aquí no cabían ambigüedades, matices ni pseudo-integraciones. Era esa cultura secular la que había que erradicar y para siempre. Y secular en lo fundamental lo había sido -como reconocen todos los especialistas- la cultura española del primer tercio del siglo XX. Para estos reaccionarios, aquella cultura secular era en última instancia intrínsecamente liberal, y hasta revolucionaria. No cabía distingo alguno. Ni nada ni nadie a quien integrar. Es más, con la guerra civil y la victoria se habrían zanjado de una vez por todas estos problemas. La Anti-España había sido derrotada por completo y en su totalidad. Sólo quedaría ya por tanto una única España, la católica y la de la tradición, la de Menéndez y Pelayo y sus epígonos. Como explicitarían Calvo Serer y Pérez Embid en su polémica con el Laín de España como problema, ya a finales de los cuarenta y principios de los cincuenta, entrar en dinámicas de rescate o recuperación de segmentos de la cultura de los derrotados, supondría una suerte de volver a las andadas, una forma de reabrir los procesos que habrian terminado por hacer inevitable la guerra civil $^{12}$.

Así pues, desde la convicción de la identidad última entre la cultura secular moderna y la cultura liberal, los nacionalcatólicos buscaban la prácticamente absoluta erradicación de ambas. Desde la diferenciación de una y otra, los fascistas querían incorporar

11 M. Menéndez Pelayo, La conciencia española. Recopilación de Antonio Tovar, Madrid, EPesA, 1948, p. XLVII-XLVIII.

12 Pedro Lain Entralgo, España como problema, Madrid, Seminario de problemas hispanoamericanos, 1949; Rafael Calvo SERER, España sin problema, Madrid, Rialp, 1949; Florentino PÉrez EMBID, Ambiciones españolas, Madrid, Editora Nacional, 1953. 
aspectos sustanciales de la cultura moderna, pero para destruir también hasta sus últimas consecuencias la cultura liberal.

Claro que, así las cosas, los fascistas podían quedar poco menos que como «liberales» por comparación. Como podían hacerlo Hitler y, sobre todo, Mussolini. Este último con tantos «indexados» a sus espaldas, o en su cerebro. Tanto que llegó a escribir La doctrina del fascismo con uno de ellos, Giovanni Gentile.

\section{Culturas políticas}

Como se habrá podido apreciar, se ha hablado aquí de nacionalcatolicismo, de nacionalismo reaccionario, de Acción Española y de sus continuadores en el franquismo, pero no de «teología política». ¿Por qué? Porque, en nuestra opinión, el concepto de teología política remite justamente a lo contrario, esto es, a una transferencia de sacralidad, a la sacralización de la política a expensas de -y en rivalidad con- la religión tradicional. Remite por ello mismo al concepto de «religión política», y entendemos que a estas alturas -como constatan los expertos, empezando por el mayor de ellos, Emilio Gentile- sí que había una religión política, la fascista. Lo que, en nuestra opinión, sería perfectamente aplicable para el caso español al sector falangista, pero no así al régimen franquista en su conjunto ni, por supuesto, a la cultura política que terminaría por ser hegemónica en el mismo, la nacionalcatólica ${ }^{13}$.

Tampoco se han utilizado aquí términos como «pensamiento católico» o similares. Básicamente porque, como es notorio, había más de un pensamiento católico. Varios más, pero nos referiremos a dos de ellos. El del integrismo reaccionario de Acción Española y epígonos, y el de la línea del llamado catolicismo político o «catolicismo oficial», el que venía del catolicismo social, de la ACNP y de AC, que se plasmó políticamente en la CEDA, que reemergió en posiciones de gobierno con Martín Artajo y Ruiz-Giménez, que se distanció del régimen ya en los años sesenta.

Es cierto que, como ha señalado pertinentemente Santos Juliá, ambos se confunden en un momento en su voluntad de recristianizar España, de reconquistar para Cristo a los españoles, y para, de paso, reconquistarlo todo ${ }^{14}$. Sin embargo, por encima y por debajo de estas innegables coincidencias, hay otras líneas de fondo que les diferencian claramente. No es este nuestro objeto central de estudio y no profundizaremos en ellos. Pero sí parece pertinente llamar la atención sobre la existencia de líneas de continuidad entre los enfrentamientos políticos de la CEDA con Renovación Española, en el alineamiento contra Acción Española de este sector con los falangistas en los años cincuenta y primeros sesenta, 0 , más adelante, en las líneas de salida del régimen ${ }^{15}$. Y no puede ser casual, en fin, que unos se «fueran» y otros se «quedaran» hasta el final.

Se trataría en suma de culturas políticas distintas; con «transversalidades», como sucede siempre, pero distintas. Señalada esta diferencia, se podría concluir la presente reflexión

$13 \mathrm{Al}$ respecto, Ismael SAZ, «Religión politica y religión católica en el fascismo español», en Carolyn BoyD (ed.), Religión y política en la España contemporánea, Madrid, CEPC, 2007, p. 33-55.

14 Santos Julia, Historias de las dos Españas, Madrid, Taurus, 2004, p. 275 y ss.

15 Según Ruiz-Giménez, la crisis que desembocó en el nuevo gobierno de 1957 tenía como perdedores a la «falange más política y revolucionaria, y el sector de Acción Católica»; lo que contraponía a la reaparición de «viejos títulos: el principal de ellos Acción Española». Citado en Pablo Hispán IgLesias DE Ussel, La política en el régimen de Franco entre 1957 y 1969. Proyectos, conflictos y luchas de poder, Madrid, CEPC, 2006, p. 23. 
con dos últimas pinceladas relativas a la cultura política del nacionalismo reaccionario. Primera. Que considerarla como una cultura política amplía las dimensiones de nuestra percepción. Desde una perspectiva «horizontal», en relación con una amplia familia política, la de un nacionalismo reaccionario que, no obstante sus innegables diferencias, va de Acción Francesa a la Associazione Nazionalista Italiana, de ésta al Integralismo Lusitano, a Acción Española e, incluso, a algunas experiencias latinoamericanas. Pero también desde una perspectiva "vertical» -la que más nos interesa ahora-, en la medida en que permite captar las líneas de continuidad que van desde Acción Española, a los protagonistas del Opus en los años cincuenta y, en lo sucesivo, a los tecnócratas.

Segunda. En este último sentido, apreciar las líneas de continuidad permite iluminar también los sucesivos momentos de confrontación entre esas culturas políticas que recorren toda la historia del régimen. Y permite igualmente romper con una de las últimas mitologías. Aquella que, incidiendo en el carácter «modernizador» de los tecnócratas, oculta sus conexiones con el nacionalismo reaccionario, con las sucesivas «generaciones» de intelectuales del nacionalismo reaccionario. Una fragmentación de los tiempos que permite la paradójica autorrepresentación de los tecnócratas como otra especie de gueto carente de apoyos sociales, casi sin plataformas de poder. Extraño gueto que había llegado a contar, una vez tras otra, con sólidos apoyos en la Iglesia, en los militares, en los medios de negocios, que, por lo menos, sirvieron para neutralizar el último intento de institucionalización falangista -el de Arrese- y que, ya en los sesenta, fue acumulando de forma imparable ministerio tras ministerio hasta el gobierno «monocolor» de 1969.

\section{Intelectuales franquistas; y después}

Incidiendo en la existencia de líneas de continuidad, hemos pretendido poner de manifiesto como las distintas corrientes intelectuales y las distintas culturas políticas desde las que los intelectuales pensaban, cambiaban, evolucionaban y actuaban, son fundamentales para explicar las dinámicas del régimen. Pero lo son también, para comprender el modo en que el régimen y sus intelectuales interactuaban, así como, en última instancia, las «líneas de salida del mismo». Todavía hoy, en efecto, hay enfoques que tienden a negar o minusvalorar la importancia de la existencia de diversas líneas en litigio. Todos nacionalcatólicos y, por ende, todos fascistas, dicen algunos; todos nacionalcatólicos $\mathrm{y}$, por tanto, ninguno fascista en sentido estricto, dicen otros; todos fascistas, más allá de sus, en última instancia, pequeñas querellas. Y también claro, están quienes sostienen que el régimen era fascista, pero que lo que se dice fascista, fascista, no había nadie. Y si, como casi todo el mundo conviene, el propio Franco no era fascista, la cosa adquiere dimensiones estratosféricas. Más aún, estaríamos ante la extraordinaria circunstancia de que los únicos fascistas de verdad, los falangistas, eran más bien «liberales», mientras que los que marcaron en el régimen «fascista» su más clara impronta reaccionara, los nacionalcatólicos, terminarían por ser modernizadores y modernizar la economía y la administración. Unos, los fascistas, estarían en los orígenes culturales de nuestra democracia, otros, los reaccionarios-modernizadores, habrían puesto las bases económicas y administrativas para nuestra actual democracia. Teniendo en cuenta que unos y otros tenían muy claro cuando se sublevaron en julio de 1936 que lo hacían para que nunca más hubiera liberalismo y democracia en España, la contradicción no puede ser más superlativa.

No. La constatación de la existencia de verdaderos intelectuales fascistas y de verdaderos intelectuales reaccionarios, alcanzando, en diversos momentos, unas posiciones de poder 
nunca alcanzadas por los intelectuales, es, como decíamos, absolutamente fundamental para entender la evolución del régimen y la de los mismos intelectuales.

Conviene subrayar que estamos hablando de fascistas «de verdad» enfrentados a la quiebra absoluta en el plano internacional de su proyecto; y estamos hablando de reaccionarios «de verdad» enfrentados a la misma quiebra en el plano internacional de su proyecto. Porque los derrotados en la II Guerra Mundial fueron ambos proyectos, no sólo el fascista. Y estos dos proyectos eran los que seguían «orientando» los destinos del régimen franquista. Lo sorprendente desde esta perspectiva, no es que muchos de estos intelectuales terminaran por alejarse del régimen, lo sorprendente es que -casi todos- lo hicieran tan tarde.

Pero, ciertamente, las líneas de salida eran diversas. Para los fascistas, en última instancia seculares, modernos y populistas se trataba de evolucionar reconstruyendo aquellos universos mentales que tan estrepitosamente habían abandonado: desde la continuidad de la cultura secular y moderna, se podía (re)conectar con la cultura liberal, con la vieja y vituperada modernidad, que era, ahora, la triunfante, casi la única. Más fácil lo tenían los «católicos oficiales» quienes ni siquiera tenían que dejar de ser católicos para hacerse demócratas. Ahí estaba, si más no, el Concilio Vaticano II con toda su carga revolucionaria; o, por decirlo de otro modo y si se nos permite el trazo grueso, para mostrar que los denostados al unísono por fascistas y nacionalcatólicos españoles, los «maritenistas», estaban en la dirección correcta. $\mathrm{Y}$, más difícil lo tenían, en fin, los nacionalistas reaccionarios, a los que ese mismo Concilio había dejado, por así decirlo, a la intemperie. Pero pudieron apostar por la modernización económica, que es lo que habían hecho siempre; por el «fin de las ideologías», que no era otra cosa que la «modernización» de la vieja idea reaccionaria de la administración sin política; y, eso sí, con muy pocas excepciones, seguir franquistas hasta el final.

\section{Vías de libertad}

Así pues, en lo fundamental, sólo ex fascistas y «católicos oficiales» pudieron aportar algo a la causa del antifranquismo, a la causa de la libertad. Pero cuánto, cuándo y cómo es otra cuestión. Y cuál fue su incidencia social, es también otra cuestión. No entraremos a fondo en ellas dada su intrínseca complejidad; la cual, por otra parte, desborda los límites cronológicos de estas páginas. Nos contentaremos por ello con una última acotación.

Tal es, que estamos totalmente de acuerdo con la afirmación de Juan Benet, recuperada y subrayada por Santos Juliá, de que los jóvenes, a los que los falangistas radicales habían llenado la cabeza con ideas de revolución, justicia social y modernidad, descubrieron que sus maestros eran de barro ${ }^{16}$. Tomaron conciencia de ello y se alejaron del Régimen, de Falange y de los maestros. Les debían, y seguirían debiendo a estos últimos, que les hubieran liberado de la «maldad» de Unamuno, Ortega o Machado. Sólo que decidieron leerlos «enteros» para ir, a partir de ahí, más allá, mucho más allá. Les debían también que las rendijas del «modernismo fascista» del que habían hecho gala les ayudaran a intuir, descubrir, acercarse y, finalmente asumir sin equívocos la otra modernidad, aquella que sus maestros habían rechazado hasta el vilipendio, la modernidad democrática, liberal y/o revolucionaria. Lo significativo, como hemos subrayado, es que -Ridruejo al margen- los maestros necesitaran una década, o más, para llegar, y no todos, y no todos del todo, a donde habían llegado sus «discípulos».

16 Santos JulıA, Historias ..., cit. p. 429 y ss. 


\section{Epílogo}

Por supuesto, no se trata de someter a una suerte de proceso a los «intelectuales de la victoria». No es esa la tarea del historiador. Diremos, así mismo, que los hombres, y en particular estos hombres, no son bloques compactos, no son unidimensionales, tienen múltiples facetas y tienen, o pueden tener, desde una incuestionable tensión moral hasta talantes de apertura mental y tolerancia hacia las inquietudes de sus discípulos. Por otra parte, los mismos maestros fascistas hicieron sus propios y largos viajes a través del fascismo -y del franquismo-; y es acerca de las especificidades de estos viajes sobre lo que el historiador debe preguntarse, indagar. Podemos reconocer también el mérito de algunas evoluciones, tanto mayor cuanto más larga era la distancia a recorrer: del fascismo más exaltado a la cultura de la libertad. Sin embargo, para que esto sea así, hay que reconocer, como punto de partida, que tal viaje existió. Porque si al principio ya se vislumbraba el final ¿dónde está el viaje?

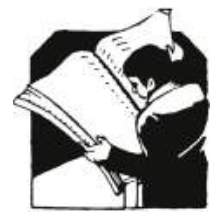

